OPEN ACCESS

Edited by:

Katherine Henrietta Leith, University of South Carolina,

United States

Reviewed by:

Cynthia Warren,

Texas Woman's University,

United States

Shanshan Lin

University of Technology

Sydney, Australia

${ }^{*}$ Correspondence:

Pálma Szabó

szabo.palma.timea@gmail.com

Specialty section:

This article was submitted to

Public Health Education and

Promotion,

a section of the journal

Frontiers in Public Health

Received: 15 June 2021 Accepted: 25 October 2021 Published: 30 November 2021

Citation:

Szabó P, Bíró É and Kósa K (2021) Readability and Comprehension of Printed Patient Education Materials.

Front. Public Health 9:725840.

doi: 10.3389/fpubh.2021.725840

\section{Readability and Comprehension of Printed Patient Education Materials}

\author{
Pálma Szabó ${ }^{1,2 *}$, Éva Bíró ${ }^{3}$ and Karolina Kósa ${ }^{1}$ \\ ${ }^{1}$ Faculty of Medicine, Department of Behavioral Sciences, University of Debrecen, Debrecen, Hungary, ${ }^{2}$ Doctoral School of \\ Health Sciences, University of Debrecen, Debrecen, Hungary, ${ }^{3}$ Faculty of Medicine, Department of Public Health and \\ Epidemiology, University of Debrecen, Debrecen, Hungary
}

Background: Health literacy, a recently determined construct plays an important role in how individuals are able to manage their health. A useful approach for the assessment of health literacy is to measure the comprehension of available patient education materials (PEMs).

Objective: We aimed at assessing the usefulness of PEMS available in Hungarian by testing comprehension of selected PEMs in different groups of users.

Methods: Comprehension of patient education materials in the domain of healthcare was tested by selecting PEMs and creating questions based on their text in 3 dimensions of health literacy: understand, process/appraise, apply/use. Twenty questions were created that could be answered without pre-existing knowledge by reading the appropriate text taken from PEMs. Comprehension was examined in four groups: laypersons, non-professional healthcare workers, 1 st year healthcare students, and 5th year medical students. Readability indices were calculated for the same texts to which questions were created.

Results: Laypersons answered $<50 \%$ of the PEMs-based questions correctly. Non-professional healthcare workers performed better with $57 \%$ of right answers but significantly worse than healthcare students or medical students. Those with at least high school qualification (maturity exam) showed significantly higher comprehension compared to those with lower educational attainment. Persons in good or very good health also had significantly better comprehension than those in less favorable health. All readability indices showed that comprehension of the tested PEMs required at least 10 years of schooling or more. Therefore, these PEMS are difficult to understand for persons with less than high school level of education.

Conclusion: Rephrasing of the investigated patient educational materials would be recommended so that they better fit the educational attainment of the Hungarian population. Evaluation of the readability and comprehensibility of other PEMs also seems warranted.

Keywords: health literacy, comprehension, patient education, healthcare workers, readability index 


\section{INTRODUCTION}

According to an early definition of the term, health literacy is the degree to which individuals have the capacity to obtain, process and understand basic health information and services to make appropriate health decisions (1). A more recent definition of Sorensen and the HLS-EU Consortium (2) based on a systematic literature review proposed a more complex definition according to which health literacy "entails people's knowledge, motivation and competences to access, understand, appraise, and apply health information in order to make judgments and take decisions in everyday life concerning healthcare, disease prevention and health promotion to maintain or improve quality of life during the life course." An integrated model, built on this wider definition identifies at least four dimensions of health literacy in three health domains: health care, disease prevention and health promotion.

Health literacy is assessed at the individual or population level using one or more of the large numbers of validated instruments $(3,4)$. International surveys found that sizable proportions of the populations in developed countries had less than sufficient levels of health literacy. For example, $36 \%$ of the adult US population had below-basic or basic level of health literacy in 2003 (5), and the proportion of persons with inadequate or problematic health literacy ranged from $28.7 \%$ in the Netherlands to $62.1 \%$ in Bulgaria in the European health literacy survey (HLS-EU) (6).

An obvious aim is to improve the level of health literacy. Until then, helping people comprehend health-related information can be achieved by creating easy-to-understand materials (7). One step in this process is to assess the comprehension and readability of existing written patient education materials (PEMs) $(8,9)$ since these are routinely used in health care and have been shown to improve self-management of various conditions $(10,11)$. In case of comprehension, understanding of relevant material by individuals is tested (12). Readability of a text is assessed by calculating various readability indices based on formulas that use the number of syllables or characters in a specific text. Indices reflect the difficulty of the vocabulary and sentences in written materials and can be assigned to a "grade level" to express the number of years of schooling which would be required to comprehend the given text.

The most frequently used readability indices are the FleschKincaid Index (FKI), the Gunning-Fog Index (GFI), the Simple Measure of Gobbledygook (SMOG) $(13,14)$, and the ColemanLiau index (CLI) (15). The former three are calculated using the number of syllables, words, and sentences in a text which are fed into a specific weighted formula to produce a total score in a range that corresponds to a particular US school level. The formula for calculating CLI uses the number of characters in a text instead of syllables. These readability indices are primarily used for English texts. However, the Flesch Reading Ease Test

Abbreviations: BRIEF, Brief Health Literacy Screening Tool; CLI, ColemanLiau index; CPC, Competency in Patient Care; FKI, Flesch-Kincaid Index; GFI, Gunning-Fog Index; HLS-EU, European Health Literacy Survey; HLS-EU 47, European Health Literacy Survey Questionnaire 47; NVS, Newest Vital Sign; PEMs, patient education materials; SMOG, Simple Measure of Gobbledygook; S-TOFHLA, Short-Test of Functional Health Literacy in Adults. from which the FKI index is calculated, the Gunning-Fog Index, and the Simple Measure of Gobbledygook were also tested and found useful in Hungarian texts (16). The CLI has also been used for languages other than English and can be used for comparing the readability of various texts in the same language, with higher numbers reflecting more difficult texts (17).

The suggested reading level for PEMs are grade $6-8$. However, the readability scores of several existing PEMs seem to be significantly higher than that in the UK, Canada and Australia $(18,19)$.

Readability assessments according to various indices have been carried out on English PEMs for patients with chronic kidney disease (20), dermatological diseases (9), and PEMs available at the point of care (21). There were similar studies carried out on PEMs for patients at menopause (22), with congestive heart failure (23), as well as on PEMs for orthopedic or rheumatology patients $(19,24)$, also for patients undergoing hand surgery (25) and for various other common health conditions $(26,27)$.

A recent paper even addressed readability for patient education material on COVID-19 (28).

Our goal was to assess the usefulness of patient education materials by a two-pronged approach, investigating both comprehension and readability. PEMs used in the Hungarian health care system were collected in the most important areas of patient-doctor interactions: scheduling an appointment, giving consent, scheduling and side-effects of medication, side-effects of surgical procedure, dietary recommendations, finding health care services, health insurance-related and ethical guidelines. Comprehension of these texts was investigated by creating questions based on the texts. Readability of the same texts was assessed by calculating four indices (FKI, GFI, SMOG and LKI).

Comprehension of PEMs was assessed in laypersons and non-professional health workers of primary health care. These workers had no professional qualification and were employed as health mediators in a large-scale model programme that was designed to introduce group practices (so-called GP clusters) in the primary care system of Hungary. These group practices also offered previously unavailable preventive services such as health status assessment, lifestyle counseling, and community health promotion programmes in regions with sizable numbers of disadvantaged patients. Non-professional workers acted as facilitators between professional workers and the serviced population with the aim of easing communication, increasing access and uptake of health services, and aiding health promotion programmes (29). Patient education was not a specific task for health mediators but they were frequently asked to read and interpret PEMs by patients in the community, so comprehension of these texts was a salient question.

\section{MATERIALS AND METHODS}

\section{Selection of Patient Education Materials}

Considering the large number of PEMs used in the Hungarian health care, we decided to limit the study to those in the domain of health care as defined by Sorensen et al. (2). Of the four dimensions in this model, the first ("accessing/obtaining 
TABLE 1 | Topics of the patient education materials selected for assessing comprehension.

\begin{tabular}{|c|c|c|c|}
\hline \multirow{2}{*}{$\begin{array}{l}\text { Domain: } \\
\text { Health } \\
\text { care }\end{array}$} & \multicolumn{3}{|c|}{ Dimensions of health literacy investigated in the present study } \\
\hline & $\begin{array}{l}\text { Understand } \\
\text { information } \\
\text { relevant to health }\end{array}$ & $\begin{array}{l}\text { Process/appraise } \\
\text { information relevant } \\
\text { to health }\end{array}$ & $\begin{array}{l}\text { Apply/use } \\
\text { information relevant } \\
\text { to health }\end{array}$ \\
\hline Issues & $\begin{array}{l}\text { 4. Consent } \\
\text { form-analyzing } \\
\text { complications } \\
\text { 5. Insurance claim } \\
6 \text {. Insurance claim } \\
\text { 11. Obtaining } \\
\text { imaging results } \\
\text { 17. General } \\
\text { prognosis of a } \\
\text { chronic disease } \\
\text { 18. Prognosis of } \\
\text { chronic disease in a } \\
\text { specific case }\end{array}$ & $\begin{array}{l}\text { 3. Potential of } \\
\text { complication based on } \\
\text { Consent form } \\
\text { 8. Dietary } \\
\text { recommendations } \\
\text { 9. Laboratory results } \\
\text { 10. Laboratory results } \\
\text { 15. Organ donation } \\
\text { law } \\
\text { 19. Side effects of } \\
\text { medication } \\
\text { 20. Side effects } \\
\text { of medication }\end{array}$ & $\begin{array}{l}\text { 1. Medication regimen } \\
\text { 2. Medication regimen } \\
\text { 7. Dietary } \\
\text { recommendations } \\
\text { 12. Opening hours of a } \\
\text { pharmacy } \\
\text { 13. Opening hours of a } \\
\text { pharmacy } \\
\text { 14. Medication regimen } \\
\text { 16. Scheduling } \\
\text { appointment } \\
\text { for checkup }\end{array}$ \\
\hline $\begin{array}{l}\text { Number } \\
\text { of } \\
\text { questions }\end{array}$ & 6 & 7 & 7 \\
\hline
\end{tabular}

information relevant to health") was omitted since this was not relevant in the present study. PEMs were selected that covered major issues of health care in the other three domains in which patients have to understand and process information and make decisions. Only patient education materials produced and distributed by the largest health care provider of the NorthEastern region of the country were selected since lay persons and patients in the target groups would most frequently receive these materials. Texts from PEMs were selected to cover the most important issues in each of the 3 dimensions as shown in Table 1.

\section{Creation of Questions for Testing Comprehension}

Selected PEMs were reviewed and texts of no more than one paragraph with information describing conditions or situations relevant to issues in one of the 3 investigated dimensions (Table 1) were identified. Questions were formulated based on the text of PEMs so that all questions could be unequivocally answered-without pre-existing knowledge-by reading and comprehending the preceding text. Each question had one right answer and at least but no more than 3 potential other (wrong) answers (altogether 2, 3 or 4 answers) to choose from. Twenty questions were formulated in 12 topics from 12 PEMs. Pilot testing was carried out by health professionals with at least 5 years of work experience who found the texts and corresponding questions to be clear and answerable, not requiring adjustment. The created questionnaire is referred to as Competency in Patient Care (CPC).

\section{Sample and Data Collection for Testing Comprehension}

Non-professional workers (health mediators) employed in the model programme were invited to participate $(n=35)$. Lay participants of a community health promoting programme were also asked to participate $(n=130)$. Data collection took place in May-June 2016. In order to compare the performance of lay persons and non-professional workers, 1st year students of physiotherapy and dietetics $(n=54)$ and medical students in their final year of education $(n=29)$ were invited to read the same texts and answer the same questions. Data collection in the latter two groups was carried out in December 2018February 2019.

\section{Evaluation of the Test of Comprehension}

The number of right answers was calculated for each respondent for all items. The proportion of right answers from all respondents was calculated for each item. The number of potential answers for each item varied between 2 and 4 . This resulted in different probabilities of chance to find the right answer for each item which was taken into account by correction in the following way. The percent of correct responses for each question in each occupational group was divided by the probability of chance given the actual number of potential answers for each question. For example, if the right answer had to be chosen from 2 answers, the probability of finding it by chance was 50\%; if the right answer had to be chosen from 4 answers, the random probability of finding the right one was $25 \%$.

\section{Statistical Analysis}

The proportion of right answers was calculated. The uncorrected proportion of right answers is shown in Table 2, and with correction (for the probability of choosing an answer randomly) in Figure 1 where the "number of responses" means the total number of responses for each question from which the right answer had to be chosen. The proportion of right answers is corrected accordingly. Out of 20 questions, 5 questions had 2 potential answers, 3 questions had 3 potential answers, and 12 questions had 4 answers from which the one right answer had to be selected. Comparison of the proportion of right answers in the various groups was carried out by the Kruskal-Wallis test. Calculations were carried out in MS 365 Excel and Stata 16.1.

\section{Assessment of Readability}

Four measures of readability were calculated for the total text of the test of comprehension. Three of those indices (Flesch Kincaid Index, Gunning-Fog Index, Simple Measure of Gobbledygook) are based on the number of syllables in a text; the fourth (Coleman-Liau index) is based on the number of characters.

To calculate the Flesch Reading Ease test, the total number of sentences, words and syllables were counted in the texts and fed into the Flesch formula to calculate the score as follows: Flesch Reading Ease score $=206.835-(1.015 \times$ ASL $)-(84.6 \mathrm{x}$ ASW) where ASL is the total word count divided by the total sentence count; ASW is the total syllable count divided by the total word count (30). Result of the Flesch Reading Ease Test 
TABLE 2 | Features of the participants by occupational/study group.

\begin{tabular}{|c|c|c|c|c|}
\hline & $\begin{array}{c}\text { Non-professional health } \\
\text { workers }\end{array}$ & Laypersons & $\begin{array}{c}\text { Students of } \\
\text { physiotherapy and } \\
\text { dietetics }\end{array}$ & Medical students \\
\hline Age (mean $\pm S D$, years) & missing & 37 years $( \pm 14.91)$ & 21 years $( \pm 1.61)$ & 24 years $( \pm 1.11)$ \\
\hline Sex (\%, males) & 15 & 10 & 6 & 28 \\
\hline \multicolumn{5}{|l|}{ Highest level of education } \\
\hline Secondary \% $(N)$ & $82(28)$ & $47(58)$ & 0 & 0 \\
\hline In progress (university students) or completed tertiary \% ( $N$ ) & 0 & $7(9)$ & $100(54)$ & $100(29)$ \\
\hline \multicolumn{5}{|l|}{ Marital status } \\
\hline Single \% $(N)$ & $12(4)$ & $27(34)$ & $100(54)$ & $100(29)$ \\
\hline Present partnership (married/cohabiting) \% $(N)$ & $68(23)$ & $49(61)$ & 0 & 0 \\
\hline Bad/very bad \% $(N)$ & $6(2)$ & $11(14)$ & 0 & 0 \\
\hline
\end{tabular}

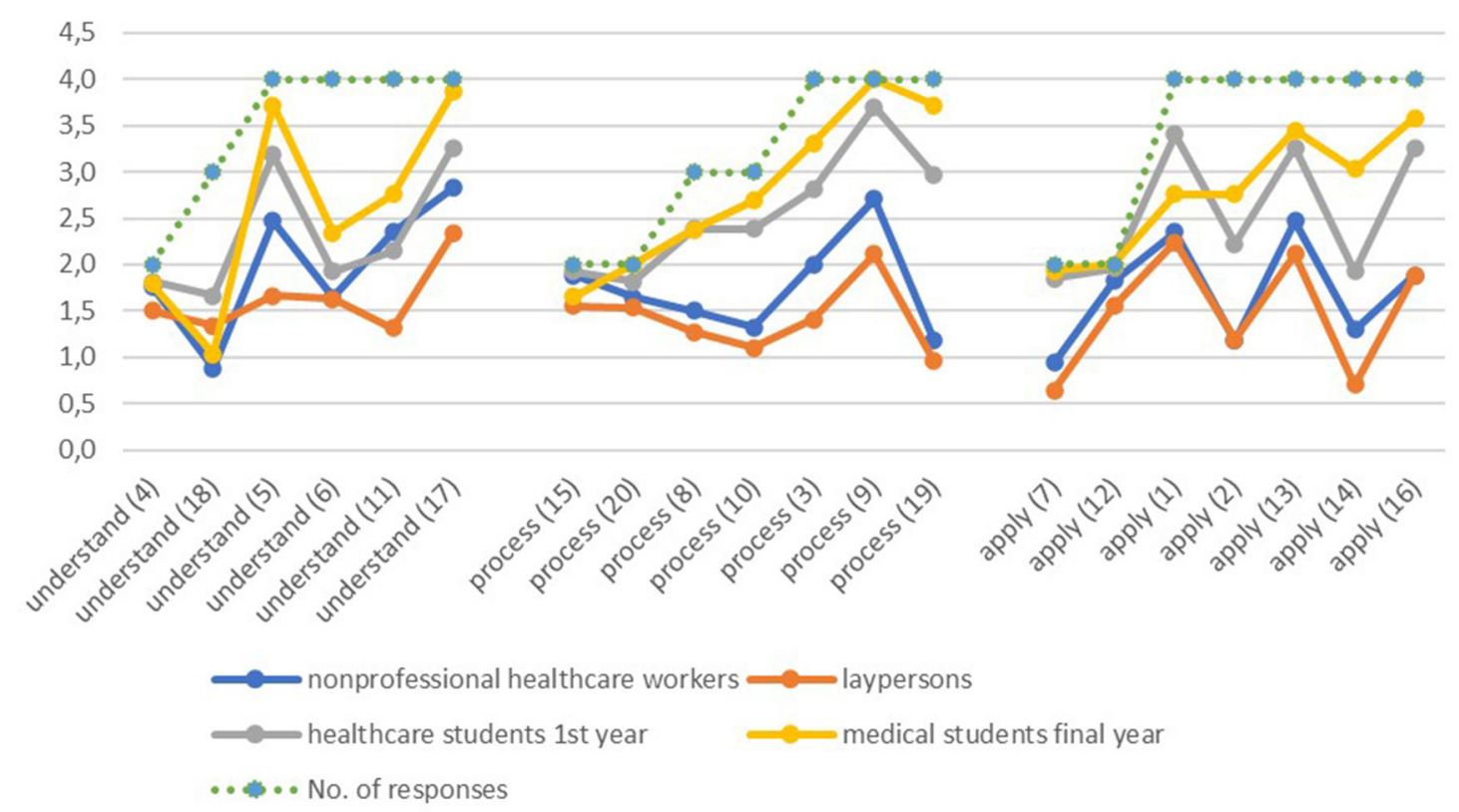

FIGURE 1 | Distribution of the corrected proportion of right answers by dimensions of health literacy by occupational groups. Green dots show the total number of responses (2, 3, or 4) on each item.

can be converted to the Flesch-Kincaid Index which specifies the grade level of the text.

The Gunning-Fog Index is calculated as follows: $0.4 \times[$ (total word count/total sentence count) $+100 \times$ (number of complex words (3 or more syllables)/total word count)] $(31,32)$.

The SMOG Index was described by McLaughlin (33): $3+\sqrt{ }$ complex words per 30 sentences (34).
The Coleman-Liau index has the following formula: CLI = $0.0588 \mathrm{~L}-0.296 \mathrm{~S}-15.8$ where $\mathrm{L}$ is the average number of letters per 100 words, $S$ is the average number of sentences per 100 words (15).

A web-based tool was used to calculate all indices (35). This calculator analyzes the grade reading level of English text using a series of readability indices, including the ones listed above. The 
TABLE 3 | Uncorrected proportion of right responses by item and occupational/study groups.

\section{Non-professional health workers \\ Lay-persons}

\section{Students of physiotherapy and \\ dietetics}

Understand information (\%)

4. Potential complications of a surgical procedure based on the consent form

5. Insurance claim after mild accident

6. Insurance claim after severe accident

11. How to request imaging results

17. General prognosis of a chronic

disease

18. Prognosis of chronic disease in a specific case

Process/appraise information (\%)

3. Identification of potential

complications in a consent form

8. Calculation of dietary intake in

diabetic diet

9. Identification of abnormal

laboratory results

10. Impact of food consumption on

laboratory results

15. Interpretation of the law on organ

donation in a specific case

19. Identification of potential side

effects of a specific medicine

20. Symptom as a potential side

effect of a specific medicine

Apply/use information (\%)

1. Application of a specific medicine

by age

2. Application of a specific medicine

in children

7. Food choice in low-fat diet

12. Which pharmacy is open now

13. Which pharmacy will be open in a specific future timepoint

14. Can a specific medicine be halved

16. Choosing a date for checkup

based on specific information
88.2

61.8

41.2

58.8

70.6

29.4

50.0

50.0

67.7

44.1

94.1

29.4

82.4

58.8

29.4

47.1

91.2

61.8

32.4

47.1
75.2

41.6

40.8

32.8

58.4

44.8

35.2

42.4

52.8

36.8

77.6

24.0

76.8

56.0

29.6

32.0

77.6

52.8

17.6

47.2
90.7

79.6

48.2

53.7

81.5

55.6

70.4

79.6

92.6

79.6

96.3

74.1

90.7

85.2

55.6

92.6

98.2

81.5

48.2

81.5
Medical students 
TABLE 4 | Comprehension in the subgroups by socio-demographic variables and subjective health.

\begin{tabular}{|c|c|c|}
\hline & $\begin{array}{l}\text { Per cent of all } \\
\text { right answers }\end{array}$ & $p$ \\
\hline \multicolumn{3}{|l|}{ By gender } \\
\hline Male $(N=28)$ & 58.93 & 0.820 \\
\hline Female $(N=213)$ & 59.86 & \\
\hline \multicolumn{3}{|l|}{ By education } \\
\hline No maturity exam $(N=102)$ & 46.03 & $<0.001$ \\
\hline Maturity exam $(N=140)$ & 69.50 & \\
\hline \multicolumn{3}{|l|}{ By marital status } \\
\hline Single $(N=121)$ & 69.66 & $<0.001$ \\
\hline Present partnership ( $N=84$ ) (married or cohabiting) & 48.27 & \\
\hline Former partnership $(N=37$ ) (divorced or widowed) & 52.43 & \\
\hline \multicolumn{3}{|l|}{ By occupation } \\
\hline Laypersons & 47.60 & $<0.001$ \\
\hline Non-professional health workers & 56.76 & \\
\hline Students of physiotherapy and dietetics & 76.76 & \\
\hline Medical students & 82.76 & \\
\hline \multicolumn{3}{|l|}{ By subjective health status } \\
\hline Good/very good $(N=153)$ & 64.54 & $<0.001$ \\
\hline Fair/bad/very bad ( $N=89)$ & 51.12 & \\
\hline
\end{tabular}

The corrected proportions of right answers are shown by each item and occupational group in Figure 1. Green dots show the potential number of responses on each item. This corrected evaluation shows even more clearly the difference between the occupational groups. The figure also reveals questions which can be considered good or easy-the ones which most respondents answered correctly $(4,12,15)$. The most difficult questions (6, 18) had a low proportion of correct answers even by medical and healthcare students. These related to the interpretation of insurance claim and organ donation law. Questions 5, 17, $10,19,16$ had the highest differentiating power which were mostly correctly answered by healthcare and medical students, and mostly incorrectly by lay persons and non-professional health mediators.

We analyzed overall comprehension, that is, the proportion of right answers by gender, education, occupational group, and health status by the Kruskal-Wallis test as described in Methods. Results are summarized in Table 4. Except for gender, significantly different comprehension was found among subgroups of other variables. Those with at least maturity exam gave 23.5\% more correct answers compared to those without ( $p$ $<0.001$ ); medical and healthcare students selected $27.6 \%$ more correct answers compared to laypersons and non-professional healthcare workers $(p<0.001)$; and those in at least good subjective health gave $13.4 \%$ more right answers than those in adequate or worse health $(p<0.001)$.

\section{Assessment of Readability in Comparison With Available Health Literacy Tools}

Readability indices such as the FKI, CLI, SMOG and GFI were calculated for our test of comprehension (Competency in Patient
TABLE 5 | Comparison of readability scores of the assessed health literacy tools.

\begin{tabular}{lccccc}
\hline & CPC & NVS & S-TOFHLA & BRIEF & HLS-EU 47 \\
\hline FKI & 10.6 & 10.6 & 12.7 & 12.4 & 12.7 \\
Gunning- & 13.2 & 12.9 & 15.3 & 14.3 & 13.5 \\
Fog & & & & & \\
SMOG & 9.8 & 9.5 & 11.6 & 10.3 & 9.9 \\
CLI & 12.0 & 11.0 & 8.0 & 11.6 & 19.0 \\
\hline
\end{tabular}

Care, CPC), and also for the Hungarian versions of some widely used tests of health literacy. CPC was found to be at 12th grade level by the Coleman-Liau Index, at 11 th grade level by FKI (10.6), at 10th grade level by the SMOG index (9.8), and at 13th grade by GFI (13.2 for GFI is defined as 'hard to read'). The readability indices of the widely used health literacy tools such as NVS, HLS-EU 47, BRIEF and S-TOFHLA were also calculated and compared to CPC. The readability indices of CPC are similar to the readability indices of validated health literacy tools, all requiring at least 10 years of education (Table 5).

\section{DISCUSSION}

Our study tested the comprehension of patient education materials in various occupational groups, among them nonprofessional health workers who are supposed to help lay people access and use health care services and understand health-related information. Overall comprehension of the investigated PEMs among laypersons was around chance, that is, their comprehension was no different from selecting answers randomly, as opposed to answers based on the provided information. Comprehension among non-professional health workers was slightly better than chance and was considerably worse than that of students of medical and health care professions. Comprehension of the latter two groups was adequate. However, medical students in their final years performed way below expectations in terms of one issue, and their performance was only slightly better than chance in 3 more issues, all of them related to comprehension of insurance claims and ethical issues.

We also tested the readability of the same materials used for comprehension testing by calculating the most frequently used readability indices such as the Flesch-Kincaid Index (FKI), Gunning-Fog Index (GFI), Simple Measure of Gobbledygook (SMOG) as their usability was previously shown for Hungarian texts (16).

Both the test of comprehension and the readability indices suggest that the language of PEMs is not tailored properly to the wide range of potential users in the Hungarian population. Considering that $45.87 \%$ of the $15-74$ year-old population had no high school diploma (no maturity exam), and $21.21 \%$ of the population had only primary education or less in 2018 according to the Hungarian Central Statistical Office (36), the investigated PEMs seem to be too difficult for those with no maturity exam. 
Readability indices (FKI, GFI, SMOG) previously used for Hungarian texts were also calculated for the text of the test of comprehension, and their scores also suggest that the language of PEMs is certainly not tailored properly to the population with lower educational attainment than high school diploma. The CLI had a much wider range being way below (S-TOFHLA) or way above (HLS-EU 47) other indices of the same questionnaire so its interpretation requires caution.

Readability indices do not necessarily reflect whether a given material is effective since they only focus on individual words and sentences, and do not take into account the active role of the reader. Therefore, these indices do not measure comprehension, and indices for the same text may differ in their grade level assignment (27). However, since they can be used to measure any text for any purpose, they can be useful as a first approach to assess patient education materials and compare the grade level of different versions of the same material.

Our results are in concert with earlier findings of the American Medical Association according to which most health care materials are written at a 10th grade level or higher although most adults read between the eighth and ninth grade level (37).

Since increasing numbers of patients use an increasing number of digital educational resources, the creation of clear and effective PEMs is more important than ever. Guidelines have been available for the creation of easy-to-understand health messages and patient education materials for more than a decade $(7,38)$. Their general recommendation is to write as simply as possible without sacrificing content or distorting meaning. However, this seems to be a tall order as the readability assessment of a number of PEMs attest $(21,39,40)$. The readability of PEMs aimed at patients with various conditions has been found to exceed that of recommended levels. Comprehension of topics involving legal matters such as insurance and medical ethics seem to be difficult even for medically qualified professionals as was shown by our questionnaire.

One of the limitations of our study is that it gives information about the readability of the selected PEMs based on text only. Charts, tables and images cannot be evaluated. Furthermore, the readability formulas were originally validated for English texts, though some of these scores were previously used with Hungarian texts (16).

Comprehension of the PEMs measured during our study does not provide in-depth information about health literacy though it can raise concerns regarding the required skills to understand, appraise and apply health information in healthcare, disease prevention and health promotion.

The strength of our study is its novelty to assess the readability of Hungarian PEMs and to reveal a gap between the recommended and the actual level of readability of such materials. Our findings underline the need for a review of patient education materials in use and evaluation of new materials before release along with the health literacy of patients who are supposed to use them. Difficulties or incomprehension of patient education materials is a grave problem since people cannot act upon information they do not comprehend. In optimal cases, patient education materials should not only be easy to comprehend but should also be tailored to the specific characteristics of the intended target group (41).

\section{CONCLUSIONS}

There seems to be a large discrepancy between the readability of the educational materials and the reading level of the general population. Considering that people with lower educational attainment are at higher risk for morbidity and mortality compared to those with higher levels of schooling, the previous group has been in a much greater need of clear health communication using plain language than the latter. More extensive research should be conducted to evaluate the readability and comprehensibility of available PEMs. In addition, rephrasing of existing education materials using simple language seems necessary, or even establishment of an organization responsible for editing such information materials as it is exemplified in Canada (42).

\section{DATA AVAILABILITY STATEMENT}

The raw data supporting the conclusions of this article will be made available by the authors, without undue reservation.

\section{ETHICS STATEMENT}

The studies involving human participants were reviewed and approved by the Model Programme had been implemented in the framework of the Swiss Contribution Programme SH/8/1 that specified the indicators for evaluation. Indicators monitored in primary health care are specified in the Hungarian Health Care Act of 1997 (1997. évi CLIV. törvény az egészségügyrol). The Programme was created on the basis of the Framework Agreement between Switzerland and Hungary (declared by 348/2007. (XII. 20.)) and signed on 20 December 2007. Ethical approval for data collection for research purposes in the Programme was issued by the Scientific and Research Ethics Committee of the Medical Research Council of Hungary (ETT-TUKEB) (16676-3/2016/EKU (0361-16). The patients/participants provided their written informed consent to participate in this study.

\section{AUTHOR CONTRIBUTIONS}

PS collected PEMs, created the questionnaire for comprehension testing, collected data, performed statistical analysis, and drafted the manuscript. EBB contributed to the creation of questionnaire, data collection, and drafting of the manuscript. KK designed the study, supervised creation of the questionnaire for comprehension testing, supervised statistical analysis, drafted the manuscript, and approved its final version. All authors have read and agreed to the published version of the manuscript. 


\section{FUNDING}

Part of the study was carried out in the framework of the Public Health Focused Model Programme for Organizing Primary Care Services Backed by a Virtual Care Service Center. The Model Programme was implemented in the framework of the Swiss Contribution Programme SH/8/1 that had been supported by a grant from Switzerland through the Swiss Contribution to Hungary. The authors were supported during the writing of the manuscript by the GINOP-2.3.2-15-2016-00005 project financed by the European Union under the European Social Fund and European Regional Development Fund. The funders had no influence on study design, data collection and analyses,

\section{REFERENCES}

1. Ratzan SC. Health literacy: communication for the public good. Health Promot Int. (2001) 16:207-14. doi: 10.1093/heapro/16.2.207

2. Sorensen K, Van den Broucke S, Fullam J, Doyle G, Pelikan J, Slonska $\mathrm{Z}$, et al. Health literacy and public health: a systematic review and integration of definitions and models. BMC Public Health. (2012) 12:80. doi: 10.1186/1471-2458-12-80

3. US National Library of Medicine. Health Literacy Tool Shed. Database of Health Literacy Measures. Available online at: https://healthliteracy.bu.edu/ (accessed June 11, 2021).

4. Liu HY, Zeng H, Shen Y, Zhang F, Sharma M, Lai WY, et al. Assessment tools for health literacy among the general population: a systematic review. Int J Env Res Public Health. (2018) 15:1711. doi: 10.3390/ijerph15081711

5. National Center for Education Statistics. National Assessment of Adult Literacy. (2003). Available online at: https://nces.ed.gov/naal/health_results. asp (accessed June 11, 2021).

6. Sorensen K, Pelikan JM, Rothlin F, Ganahl K, Slonska Z, Doyle G, et al. Health literacy in Europe: comparative results of the European health literacy survey (HLS-EU). Eur J Public Health. (2015) 25:1053-8. doi: 10.1093/eurpub/ckv043

7. Centers for Disease Control and Prevention (CDC). Simply Put; A Guide for Creating Easy-to-Understand Materials. 3rd ed. Georgia: U.S. Department of Health and Human Services (2009). Available online at: https://stacks.cdc.gov/ view/cdc/11938 (accessed June 11, 2021).

8. Fajardo MA, Weir KR, Bonner C, Gnjidic D, Jansen J. Availability and readability of patient education materials for deprescribing: an environmental scan. Brit J Clin Pharmacol. (2019) 85:1396-406. doi: 10.1111/bcp.13912

9. Prabhu AV, Gupta R, Kim C, Kashkoush A, Hansberry DR, Agarwal $\mathrm{N}$, et al. Patient education materials in dermatology: addressing the health literacy needs of patients. JAMA Dermatol. (2016) 152:9467. doi: 10.1001/jamadermatol.2016.1135

10. US National Library of Medicine. Choosing Effective Patient Education Materials. (2019). Available online at: https://medlineplus.gov/ency/ patientinstructions/000455.htm (accessed June 11, 2021).

11. Coulter A. Evidence based patient information. Bmj-Brit Med J. (1998) 317:225-6. doi: 10.1136/bmj.317.7153.225

12. Jubelirer S, Linton J, Magnetti S. Reading versus comprehension: implications for patient education and consent in an outpatient oncology clinic. J Cancer Educ. (1994) 9:26-9. doi: 10.1080/08858199409528261

13. Centers for Medicare and Medicaid Services (CMS). Toolkit for Making Written Material Clear and Effective. Part 7. (2010). Available online at: https:/www.cms.gov/Outreach-and-Education/Outreach/ WrittenMaterialsToolkit/Downloads/ToolkitPart07.pdf (accessed June 11, 2021).

14. Health Literacy Innovations. Health Literacy Advisor. Available online at: https://www.healthliteracyinnovations.com/products/hla.php (accessed June 14, 2021).

15. Coleman M, Liau T. A computer readability formula designed for machine scoring. J Appl Psychol. (1975) 60:283-284. doi: 10.1037/h0076540 interpretation of results, writing of the manuscript or the decision to submit it for publication.

\section{ACKNOWLEDGMENTS}

The authors express their gratitude to Drs. János Cséki, Gábor Benkő, István Völgyi, and János Szabó, Head GPs (directors), and to Éva Gombkötö, Edit Szabó, Ágnes Elek, and Adrienn Csilla Tóth as Public Health Coordinators of the GP clusters, supervisors of the non-professional workers for their help in data collection among non-professional health workers and lay persons. Cintia Katona contributed to data collection among students.
16. Dóra L. Olvashatósági tesztek: elmélet és gyakorlat. Képzés és Gyakorlat. (2019) 17:21-34. doi: 10.17165/TP.2019.2.2

17. Tillman R, Hagberg L. Readability Algorithms Compatibility on Multiple Languages. Stockholm Degree Project. Stockholm: Kungliga Tekniska Högskolan (2014).

18. Cheng C, Dunn M. Health literacy and the Internet: a study on the readability of Australian online health information. Public Health. (2015) 39:309-14. doi: 10.1111/1753-6405.12341

19. Oliffe M, Thompson E, Johnston J, Freeman D, Bagga H, Wong PKK. Assessing the readability and patient comprehension of rheumatology medicine information sheets: a cross-sectional Health Literacy Study. BMJ Open. (2019) 9:e024582. doi: 10.1136/bmjopen-2018-024582

20. Morony S, Flynn M, McCaffery KJ, Jansen J, Webster AC. Readability of written materials for CKD patients: a systematic review. Am J Kidney Dis. (2015) 65:842-50. doi: 10.1053/j.ajkd.2014.11.025

21. Stossel LM, Segar N, Gliatto P, Fallar R, Karani R. Readability of patient education materials available at the point of care. J Gen Intern Med. (2012) 27:1165-70. doi: 10.1007/s11606-012-2046-0

22. Charbonneau DH. Health literacy and the readability of written information for hormone therapies. J Midwifery Womens Health. (2013) 58:26570. doi: 10.1111/jmwh.12036

23. Kher A, Johnson S, Griffith R. readability assessment of online patient education material on congestive heart failure. Adv Prev Med. (2017) 2017:9780317. doi: 10.1155/2017/9780317

24. Badarudeen S, Sabharwal S. Assessing readability of patient education materials: current role in orthopaedics. Clin Orthop Relat Res. (2010) 468:2572-80. doi: 10.1007/s11999-010-1380-y

25. Hadden K, Prince LY, Schnaekel A, Couch CG, Stephenson JM, Wyrick TO. Readability of patient education materials in hand surgery and health literacy best practices for improvement. J Hand Surg Am. (2016) 41:82532. doi: 10.1016/j.jhsa.2016.05.006

26. McInnes N, Haglund BJA. Readability of online health information: implications for health literacy. Inform Health Soc Care. (2011) 36:17389. doi: 10.3109/17538157.2010.542529

27. Imoisili O, Levinsohn E, Pan C, Howell B, Streiter S, Rosenbaum J. Discrepancy between patient health literacy levels and readability of patient education materials from an electronic health record. Health Lit Res Pract. (2017) 1:e203-7. doi: 10.3928/24748307-20170 918-01

28. Szmuda T, Özdemir C, Ali S, Singh A, Syed MT, Słoniewski P. Readability of online patient education material for the novel coronavirus disease (COVID19): a cross-sectional health literacy study. Public Health. (2020) 185:215. doi: 10.1016/j.puhe.2020.05.041

29. Kosa K, Katona C, Papp M, Furjes G, Sandor J, Biro K, et al. Health mediators as members of multidisciplinary group practice: lessons learned from a primary health care model programme in Hungary. BMC Fam Pract. (2020) 21:19. doi: 10.1186/s12875-020-1092-7

30. Flesch R. A new readability yardstick. J Appl Psychol. (1948) 32:22133. doi: $10.1037 / \mathrm{h} 0057532$ 
31. Simon Bond. Gunning-Fog index calculator. Available online at: http:// gunning-fog-index.com/ (accessed June 11, 2021).

32. Gunning R. The Technique of Clear Writing. Toronto, ON: McGrawHill (1952).

33. McLaughlin G. SMOG grading: a new readability formula. J Read. (1969) 12:639-46.

34. My Byline Media. The SMOG Readability Formula. Available online at: https:// readabilityformulas.com/smog-readability-formula.php (accessed June 11, 2021).

35. My Byline Media. Automatic Readability Checker. Available online at: https://readabilityformulas.com/free-readability-formula-tests.php (accessed June 11, 2021).

36. Central Statistical Office. Number of 15-74 Year Old Persons by Educational Attainment, by Gender. (1998). Available online at: https:// www.ksh.hu/docs/hun/xstadat/xstadat_eves/i_qlf015.html (accessed June 11, 2021).

37. Safeer RS, Keenan J. Health literacy: the gap between physicians and patients. Am Fam Physician. (2005) 72:463-8.

38. National Cancer Institute. Clear \& Simple: Developing Effective Print Materials for Low-literate Readers. Washington, DC: DHHS (1995).

39. Cherla DV, Sanghvi S, Choudhry OJ, Liu JK, Eloy JA. Readability assessment of internet-based patient education materials related to endoscopic sinus surgery. Laryngoscope. (2012) 122:1649-54. doi: 10.1002/lary. 23309

40. Strachan PH, de Laat S, Carroll SL, Schwartz L, Vaandering K, Toor GK, et al. Readability and content of patient education material related to implantable cardioverter defibrillators. J Cardiovasc Nurs. (2012) 27:495504. doi: 10.1097/JCN.0b013e31822ad3dd

41. World Health Organization. WHO Principles for Effective Communications. Available online at: https://www.who.int/about/communications/principles (accessed September 25, 2021).

42. Government of Canada. Technical Committee for Plain Language. Available online at: https://accessible.canada.ca/creating-accessibility-standards/ technical-committee-plain-language (accessed June 14, 2021).

Conflict of Interest: The authors declare that the research was conducted in the absence of any commercial or financial relationships that could be construed as a potential conflict of interest.

Publisher's Note: All claims expressed in this article are solely those of the authors and do not necessarily represent those of their affiliated organizations, or those of the publisher, the editors and the reviewers. Any product that may be evaluated in this article, or claim that may be made by its manufacturer, is not guaranteed or endorsed by the publisher.

Copyright (C) 2021 Szabó, Bíró and Kósa. This is an open-access article distributed under the terms of the Creative Commons Attribution License (CC BY). The use, distribution or reproduction in other forums is permitted, provided the original author(s) and the copyright owner(s) are credited and that the original publication in this journal is cited, in accordance with accepted academic practice. No use, distribution or reproduction is permitted which does not comply with these terms. 